\title{
Functional Organization of Human Intraparietal and Frontal Cortex for Attending, Looking, and Pointing
}

\author{
Serguei V. Astafiev, ${ }^{1}$ Gordon L. Shulman, ${ }^{2}$ Christine M. Stanley, ${ }^{1}$ Abraham Z. Snyder, ${ }^{1,2}$ David C. Van Essen, ${ }^{3}$ and \\ Maurizio Corbetta ${ }^{1,2,3}$ \\ ${ }^{1}$ Department of Radiology, Mallinckrodt Institute of Radiology, and Departments of ${ }^{2}$ Neurology and ${ }^{3}$ Anatomy and Neurobiology, Washington University \\ School of Medicine, St. Louis, Missouri 63110
}

We studied the functional organization of human posterior parietal and frontal cortex using functional magnetic resonance imaging (fMRI) to map preparatory signals for attending, looking, and pointing to a peripheral visual location. The human frontal eye field and two separate regions in the intraparietal sulcus were similarly recruited in all conditions, suggesting an attentional role that generalizes across response effectors. However, the preparation of a pointing movement selectively activated a different group of regions, suggesting a stronger role in motor planning. These regions were lateralized to the left hemisphere, activated by preparation of movements of either hand, and included the inferior and superior parietal lobule, precuneus, and posterior superior temporal sulcus, plus the dorsal premotor and anterior cingulate cortex anteriorly. Surface-based registration of macaque cortical areas onto the map of fMRI responses suggests a relatively good spatial correspondence between human and macaque parietal areas. In contrast, large interspecies differences were noted in the topography of frontal areas.

Key words: fMRI; parietal cortex; frontal cortex; attention; eye movements; arm pointing

\section{Introduction}

The functional organization of human posterior parietal cortex (PPC) and its relationship to the PPC in the macaque monkey are primarily unknown. The parietal lobe, as defined by conventional geographic landmarks, occupies approximately one-fifth of the total neocortex in both humans and monkeys (Van Essen and Drury, 1997). However, there is indirect evidence that the PPC in humans is preferentially expanded compared with monkeys, given that neighboring occipital visual areas [visual area 1 (V1), V2, and middle temporal (MT)] in the two species have different geographic locations; V1 and V2 extend more laterally, and MT is positioned more dorsally in macaques compared with humans (Van Essen et al., 2001). This difference may be related to a relative expansion of the human inferior parietal lobule and to development of new cortical fields (e.g., Brodmann 39, 40) (Brodmann, 1905; Eidelberg and Galaburda, 1984). Alternatively, human and macaque PPC may share a similar architectural plan, but human areas may be relatively enlarged (Van Essen et al., 2001). The first hypothesis predicts a relative shift in the topographical position of homologous areas to accommodate the presence of new areas in humans; the second hypothesis predicts a good spatial registration of homologous areas in the two species. Similar hypotheses can be explored for the frontal cortex (FC), which is substantially expanded in humans ( $~ 36 \%$ of neocortex) compared with macaques ( $\sim 25 \%$ of neocortex) (Brod-

Received Nov. 18, 2002; revised Feb. 26, 2003; accepted March 20, 2003

This research was supported by National Institutes of Health Grants EY00379, NS06833, and MH60974 (National Institute of Mental Health, National Science Foundation, National Cancer Institute, National Library of Medicine, and National Aeronautics and Space Administration) and by the J. S. McDonnell Foundation.

Correspondence should be addressed to Maurizio Corbetta, Department of Neurology, Washington University School of Medicine, 4525 Scott Avenue, St. Louis, M0 63110. E-mail: mau@npg.wustl.edu.

Copyright $\odot 2003$ Society for Neuroscience $\quad$ 0270-6474/03/234689-11\$15.00/0 mann, 1905; Walker, 1940; Van Essen and Drury, 1997; Petrides and Pandya, 1999; Van Essen, 2003).

In an initial exploration of these hypotheses, we first studied the distribution of preparatory signals in human PPC and FC for "attention," rapid eye movements ("saccades"), and arm movements ("pointing") using functional magnetic resonance imaging (fMRI). Then, we compared the human functional maps with a map of architectonic areas in the macaque brain that was deformed to the human cortex using computerized registration of the cortical surfaces between the two species.

We focused on preparatory signals because different regions in monkey PPC and FC code for the planning of different types of movements and for shifts of attention. The lateral intraparietal area (LIP), located on the lateral bank of the intraparietal sulcus (IPS), is relatively more active when a monkey prepares to look at a target rather than reach toward it (Snyder et al., 1997). Conversely, a parietal reach region (PRR), located more posteriorly and medially along the IPS, is more active during the preparation of a reach movement than an eye movement (Snyder et al., 1997). Signals that are related to the allocation of spatial attention have been reported both in eye-related (e.g., LIP) and arm-related (e.g., PRR) areas, often on the same neurons that show effectorspecific modulations (Colby and Goldberg, 1999; Calton et al., 2002; Bisley and Goldberg, 2003). Similar distinctions have been proposed in the monkey frontal lobe. The frontal eye field (FEF) is involved in the preparation and execution of voluntary and visually guided saccadic eye movements (Bizzi, 1968; Bruce et al., 1985), whereas the dorsal premotor area is involved in planning visually guided reaching movements (Passingham, 1996; Kalaska et al., 1997; Wise et al., 1997). Attention-related modulations have been reported both in the FEF (Bruce et al., 1985; Thompson et al., 1997) and in the dorsal premotor cortex (Di Pellegrino and Wise, 1993). This functional specialization is supported by recip- 
rocal connections that link frontoparietal areas with similar functional properties (Cavada and Goldman-Rakic, 1989; Wise et al., 1997; Lewis and Van Essen, 2000; Marconi et al., 2001).

On the basis of these functional distinctions, we hypothesized that human PPC regions, homologous to LIP and PRR areas in macaque, will be selectively recruited during the preparation of saccadic eye movements or pointing hand movements, respectively. Moreover, a similar distinction will be observed in the FEF (for eye movements) and dorsal premotor (for pointing) in frontal cortex. Finally, regions involved in covertly directing attention to a peripheral location will overlap with regions involved in saccadic and pointing preparation, because spatial information is used by both eye- and arm-selection systems to plan a response.

\section{Materials and Methods}

Subjects. Fifteen subjects were recruited from the Washington University (St. Louis, MO) community for experiment 1 . Eleven subjects participated in experiment 2. Informed consent was obtained in accordance with procedures approved by the local human studies committee. All subjects were strongly right-handed as measured by the Edinburgh Handedness Inventory and had normal or corrected-to-normal vision and normal neurological history.

Apparatus. Stimuli were generated with an Apple G4 Macintosh computer (Apple Computers, Cupertino, CA) using PsyScope 1.2.5 PPC software (Carnegie Mellon University, Pittsburgh, PA). In the magnetic resonance (MR) scanner, stimuli were projected using an Epson PowerLite $703 \mathrm{c}$ liquid crystal display projector (Epson America, Long Beach, CA) onto a small Plexiglas screen that was positioned within reaching distance in front of the subject and viewed through a periscope mirror attached to the head coil. The periscopic mirror did not introduce any distortion or scaling of the visual field. Eye position was monitored with an ASL 504 (Applied Science Laboratories, Bedford, MA) eye-tracker during both behavioral and fMRI sessions. During the behavioral session, surface electromyographic (EMG) activity was recorded from surface electrodes positioned on the right arm deltoid muscle using a BIOPAC MP100 system (BIOPAC Systems, Santa Barbara, CA).

Task and procedures. A fixation cross-hair was displayed inside a gray diamond (size, $1.6^{\circ}$ ) on a black background at all times. A change in the color of the fixation point from red to green indicated the start of a trial. Simultaneously, one side of the diamond was brightened for $100 \mathrm{msec}$ indicating either a left or a right location (cue stimulus). After a random delay (4.76-5.86 sec after the offset of the cue in experiment $1 ; 2.6-3.7$ sec after the offset of the cue in experiment 2), a white asterisk (target) was flashed for $100 \mathrm{msec}$ at $7.3^{\circ}$ to the left or right of fixation. The asterisk had to be detected in the attention, saccade, and pointing task (see below). The target occurred at the cued location on $73 \%$ of the trials $(75 \%$ in experiment 2) (valid trial), and at the opposite location on $27 \%(25 \%$ in experiment 2) of the trials (invalid trial). In the attention condition, a random digit (1-9) was occasionally presented (not presented, presented once, or presented twice in a block of trials) instead of the asterisk (see below). After another interval $(0.435-1.535 \mathrm{sec})$ that yielded a fixed trial (cue plus test) duration of $6.5 \mathrm{sec}$ ( $4.33 \mathrm{sec}$ in experiment 2), the fixation point changed color from green to red to indicate the end of the trial. Trials were separated by a random intertrial interval (ITI) of 2.16-6.49 $\mathrm{sec}$, in which the fixation point remained red. For $21 \%$ (20\% in experiment 2) of the trials, only the cue stimulus was presented, followed by a fixed interval of $4.23 \mathrm{sec}(2.07 \mathrm{sec}$ in experiment 2$)$ before the start of the ITI. The presentation of cue-only trials was necessary to separate cue and target fMRI responses within a trial (Shulman et al., 1999; Ollinger et al., 2001a,b).

In experiment 1 , subjects were studied in separate behavioral and fMRI sessions. Three different tasks were performed. In the pointing task, subjects used the cue to prepare a pointing movement with their right index finger toward the indicated location and maintained this set during the ensuing delay without moving the hand. In the scanner, the right hand was positioned in the middle of the abdomen in a relaxed posture with the index finger extended and all other fingers flexed. The right shoulder and arm were supported and immobilized with Velcro straps attached to the scanner bed. When the target was flashed, subjects pointed as quickly as possible in the direction of the target location (without touching the screen) and then returned to the starting position. Pointing involved rotation of the wrist without movements of the shoulder or the arm. In the behavioral session, subjects sat in front of a computer screen. They rested their index finger on a response key during the cue period and pointed in the direction of the target location without touching the screen. Key-press reaction times (RTs) were measured for valid and invalid trials. In the saccade task, the cue was used to prepare a saccadic eye movement to the left or right. After the target was flashed, subjects looked at its location and then quickly looked back at the fixation point. In the attention task, subjects covertly shifted and maintained attention to the cued location and returned attention to the center after the presentation of the target. In the fMRI session, subjects reported how many times (not at all, once, or twice) a random digit was presented in the course of a block of trials. This secondary task ensured that subjects attended to the peripheral target on each trial. Mean accuracy was $97 \%$ correct. In the behavioral session, key-press RTs were measured for valid and invalid trials. Both EMG activity from the right deltoid muscle and eye movement position were recorded in all conditions. In the behavioral session, subjects completed two blocks of 40 trials each for each condition. In each fMRI session, a subject performed 140 trials per condition, and the group statistical analysis was based on a total of 2100 trials per condition (140 trials $\times 15$ subjects). Single subject analyses involved two scanning sessions ( 280 trials per condition).

In experiment 2, only the pointing task was run. In different blocks/ scans, subjects used either the left or the right hand. Vision of the hand was occluded by a modification to the periscopic mirror, and an infrared video camera was used to monitor the position of the hand and confirm that no movement had occurred during the cue period. Each subject performed 210 trials per condition, and the group analysis was based on 2310 trials per condition ( 210 trials $\times 11$ subjects).

fMRI scan acquisition and data analysis. A Siemens whole-body $1.5 \mathrm{~T}$ Vision MRI scanner (Siemens AG, Munich, Germany) and asymmetric spin-echo, echoplanar sequence were used to measure blood oxygenation level-dependent (BOLD) contrast over the entire brain [repetition time (TR), $2.165 \mathrm{sec}$; echo time (TE), $37 \mathrm{msec}$; flip angle, $90^{\circ}$; 16 contiguous $8 \mathrm{~mm}$ axial slices, $3.75 \times 3.75 \mathrm{~mm}$ in-plane resolution]. Anatomical images were acquired using a sagittal magnetization-prepared rapid acquisition gradient echo (MP-RAGE) sequence (TR, $97 \mathrm{msec}$; TE, $4 \mathrm{msec}$; flip angle, $12^{\circ}$; inversion time, $300 \mathrm{msec}$ ). Functional data were realigned within and across scanning runs to correct for head motion using an eight parameter (rigid body plus in-plane stretch) crossmodal registration similar to the method described by Andersson et al. (1995). A wholebrain normalization factor was applied to each scan to correct for changes in signal intensity between scans. Differences in the time of acquisition of each slice within a frame were compensated by sinc interpolation. For each subject, an atlas transformation (Talairach and Tournoux, 1988) was computed on the basis of an average of the first frame of each functional run and MP-RAGE structural images to the atlas representative target using a 12 parameter general affine transformation. Functional data were interpolated to $2 \mathrm{~mm}$ cubic voxels in atlas space. The atlas representative MP-RAGE target brain (711-2B) was produced by mutual coregistration (12 parameter affine transformations) of images obtained in 12 normal subjects (Snyder, 1995). The BOLD signal in each subject was analyzed with a "within-trial" linear regression model that estimated separate time courses during the cue and test periods for each trial type, without assuming a shape for the hemodynamic response (Ollinger et al., 2001a). The model included terms on each scanning run for an intercept, linear trend, and temporal high-pass filter with a cutoff frequency of $0.009 \mathrm{~Hz}$. Time courses from the within-trial model were put into atlas space using the atlas transformation. Group analyses were conducted using voxel-wise random-effect ANOVAs. Subjects were treated as a random effect so that all results generalized across the population. Correlations across time points were corrected by adjusting the degrees of freedom (Ollinger and McAvoy, 2000). Statistical images were corrected for multiple comparisons over the entire brain $(p<0.05)$, using a magnitude threshold derived from Monte-Carlo simulations that takes into account the number of contiguous activated voxels (Forman et 
al., 1995). Coordinates of each cluster of activation were identified by an automated algorithm that searched for local maxima and minima (Mintun et al., 1989). Individual subject analyses were based on a crosscorrelation of the estimated BOLD response in each voxel with an assumed hemodynamic response function, calculated by convolving a delayed gamma function (Boynton et al., 1996) with a rectangular function of the event duration (e.g., cue period duration, $4.32 \mathrm{sec}$ ). In experiment 1, within-subject ANOVAs were run during the cue period with MR frame (1-8), task (pointing, saccade, and attention), and cue direction (left and right) as factors. During the target period, separate ANOVAs were run with MR frame (1-8), task (pointing, saccade, and attention), target visual field (left and right), and target validity (valid and invalid) as factors. In experiment 2 , the factor task included only two levels (left hand, right hand).

Visualization of fMRI data and surface-based registration of macaque and human atlases. To facilitate visualization of results and the comparison across species, the group-averaged functional data were mapped to the Human Colin surface-based atlas (Van Essen et al., 2002; Van Essen, 2003). This atlas includes a high-resolution structural MRI volume of an individual brain (Holmes et al., 1998) that was registered using the method of Snyder (1995) to the representative MP-RAGE target brain (711-2B) used for the atlas transformation (see above). A surface reconstruction of the left and right hemisphere of the Human Colin brain was generated using the SureFit segmentation method (Van Essen et al., 2001). Functional data were mapped onto the Human Colin atlas brain (three-dimensional and surface) by assigning each surface node the $z$-score value associated with the voxel in which it resides.

The pattern of cortical convolutions in the Colin atlas brain lies well within the range of normal variability according to the following criteria. (1) The pattern of major sulci in the Colin left and right hemispheres is within the range that occurs commonly in the atlas of 25 brains described by Ono et al. (1990). (2) After atlas registration, the Colin left and right hemispheres were compared with the atlas average brain that we use as the target for the Talairach transformation (711-2B). There was good correspondence in the location of major sulci (including the calcarine, postcentral, central, superior frontal, and superior temporal sulci plus the Sylvian fissure) in the Colin brain and the corresponding (although fuzzier) sulci in the average atlas brain. As an example, the average location of the intersection of the left superior frontal sulcus and precentral sulcus was $-25,-13,52(x, y, z)$ in Colin and $-25,-13,52$ in 711-2B; the midpoint of the right postcentral sulcus was $41,-31,46$ in Colin and $47,-31,46$ in 711-2B; the midpoint of the left central sulcus was -35 , $-33,56$ in Colin and $-33,-29,56$ in 711-2B. (3) The Colin left and right hemispheres were also compared with the average brain obtained by averaging the individual brains of the subjects participating in this experiment after atlas transformation (to the target 711-2B). Once again, we found good correspondence in the location of major sulci (central, postcentral, superior frontal, precentral, and intraparietal) and in the location of functional regions in relation to anatomical landmarks.

Surface-based registration of the macaque and human cortex was achieved by first drawing landmarks on cortical flat maps of each hemisphere of the macaque and human surface-based atlases (Van Essen, 2002, 2003) (available at http://brainmap.wustl.edu/caret/). These landmarks, chosen to reflect likely homologous domains, include the fundus of the central sulcus (near the boundary between somatosensory and motor cortex), the fundus of the Sylvian fissure (near the boundary between somatosensory and auditory cortex), the frontal pole, the boundaries of V1, V2, and MT + as described by Van Essen and colleagues (Van Essen et al., 2001; Van Essen, 2003), and the boundaries of neocortex along the medial wall. To avoid confounds associated with artificial cuts on the flat maps, the landmarks were first projected to macaque and human spherical maps, the registration was applied to the spherical maps, and the deformed visual areas were then projected onto the inflated hemisphere used in the illustrations (available at http://brainmap. wustl.edu/caret/). The macaque map (before and after deformation) includes the Lewis and Van Essen (2000) partitioning scheme.

\section{Results}

In a behavioral session, we measured the efficacy of the central cue in speeding the response to a target at the attended location. Reaction times were faster to valid targets than invalid targets, both during pointing (388 vs $423 \mathrm{msec} ; t_{(14)}=-4.28 ; p=0.001$ ) and attention (301 vs $332 \mathrm{msec} ; t_{(14)}=-4.86 ; p<0.0001$ ). Central fixation measured with an infrared eye tracker was similar during the cue period in all three conditions and during the target period in attention and pointing tasks. There was no differential EMG activity from the arm across tasks during the cue period or in the saccade and attention tasks during the target period.

We monitored eye position in the fMRI session. The results from the analyses of all 15 subjects were confirmed in subanalyses on the 11 subjects with acceptable eye movement records that included only trials in which accurate fixation $\left( \pm 1.5^{\circ}\right)$ was maintained.

We first considered the relationship between attention and saccade conditions during the cue period. Figure $1, A$ and $B$, shows statistical maps of the group fMRI signal during the cue period for the attention and saccade tasks, respectively, displayed on an inflated surface of the left hemisphere of an atlas brain (Van Essen et al., 2001) (Table 1S, supplemental material, available at www.jneurosci.org). In both tasks, cue-related signals were observed bilaterally in the occipital cortex, in the PPC along the horizontal segment of the IPS [anterior IPS (aIPS) and posterior IPS (pIPS)], and in the frontal cortex at the junction of the precentral and superior frontal sulcus [putative human FEF (hFEF)]. The BOLD response in the occipital cortex was transient, reflecting a sensory response to the cue (data not shown); conversely, the response in the IPS and FEF was sustained in both tasks throughout the delay period (Fig. $1 A, B$ ) (time courses saccade vs attention). In previous work, we have shown that sustained responses in the IPS and FEF correlate with encoding and maintenance of a spatial cue (Corbetta et al., 2000). An interaction map of the two tasks (Fig. $1 D$, Table $1 S$ ) revealed only a small region in the left anterior precuneus $(\mathrm{aPCu})(x, y, z=-3,-51$, 58) that was more strongly active during attention than eye movement preparation. This region is close to one reported exclusively for shifting attention $(x, y, z=-4,-52,52)$ (Simon et al., 2002). Hence, PPC and frontal response were primarily similar during attention and saccade tasks.

Next, we considered whether preparing a pointing response involved a distinct functional network. Figure $1 C$ shows areas of activation during pointing preparation. Intraparietal (aIPS, pIPS) regions that were active during attention and eye movement preparation were also recruited during pointing preparation. These responses were generally larger during pointing than attention (nonsignificantly, Table $1 S$ ) and saccade (significantly, Table $1 S$ ) tasks. Surprisingly, we also observed preparatory responses during pointing in the FEF, an area traditionally associated with oculomotor preparation (see maps and time courses in Fig. 1A-C; Table $1 S$ ). Finally, a larger extent of PPC and frontal cortex were recruited exclusively during pointing preparation (Fig. 1C,E, Table 1S). The interaction map between the pointing and saccade tasks (Fig. $1 E$ and time courses) shows stronger signals for pointing preparation in a region on the lip of the inferior parietal lobule (IPL/aIPS), a cluster in the superior parietal lobule $(\mathrm{SPL})$ extending medially into the precuneus $(\mathrm{PCu})$ and posterior cingulate, regions within the angular gyrus (AG) and supramarginal gyrus (SMG) and the middle segment of the superior 


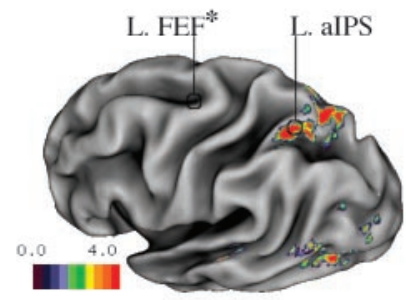

A. Attention

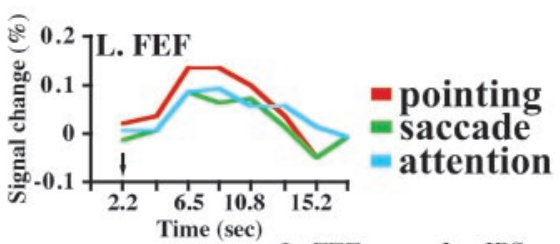

Time (sec)

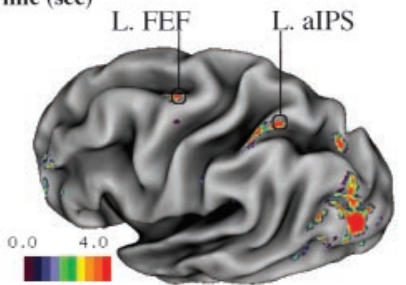

B. Saccade preparation
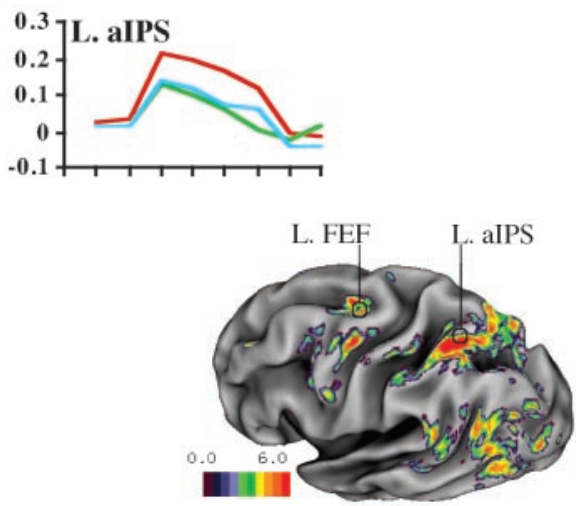

C. Pointing preparation

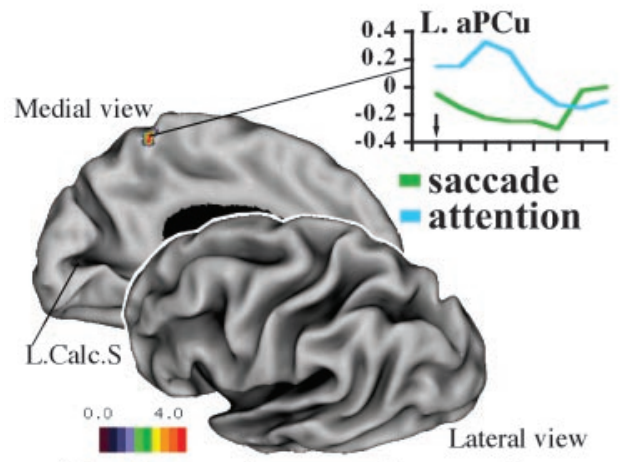

D. Attention vs. Saccade preparation

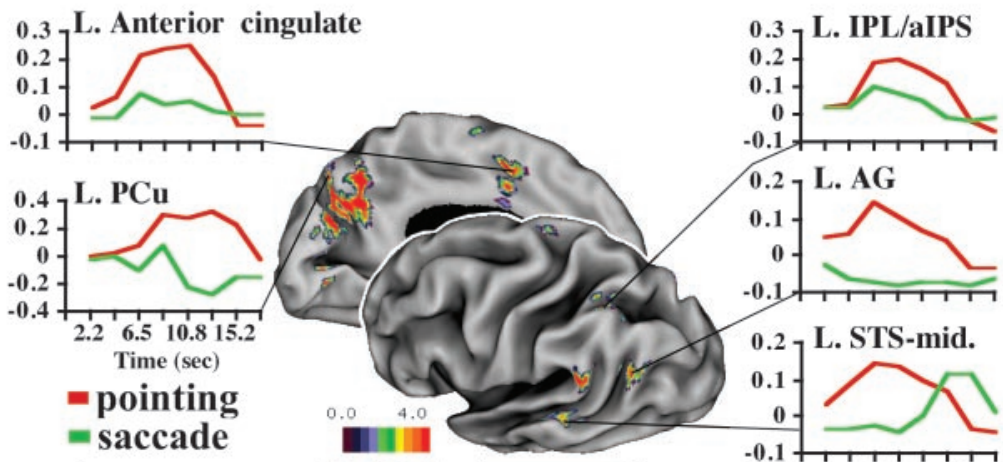

E. Pointing vs. Saccade preparation
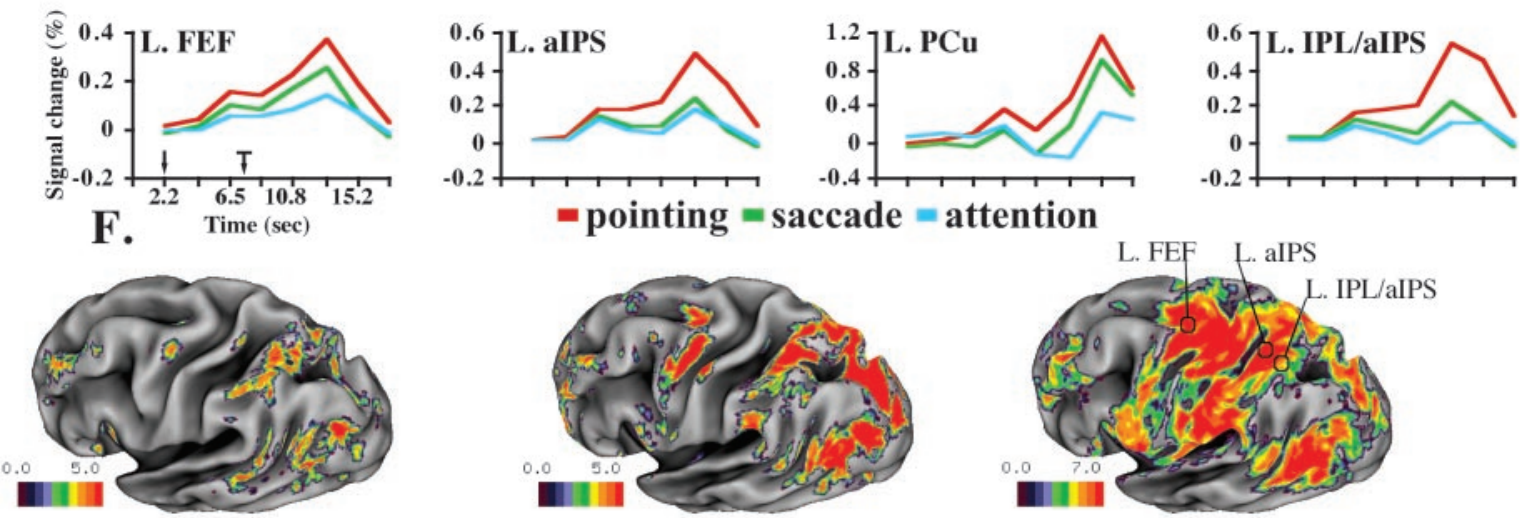

\section{G. Attention + detection

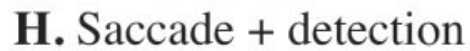 \\ I. Pointing + detection}

Figure 1. BOLD responses on inflated surface of the left hemisphere of the Colin brain (Van Essen et al., 2001). The Front plane indicates the dorsolateral view of left hemisphere; the back plane gives the medial view. Color scale indicates z-scores. Cue period is as follows: A, Group-average ANOVA F-map, transformed to z-map and multiple-comparison corrected (F(z)mc) during covert attention. B, Preparation of saccadic eye movement. C, Preparation of pointing movement with right hand. Graphics indicate group-average BOLD time courses averaged over cue direction during attention (blue), saccade (green), and pointing (red). The $y$-axis indicates the percentage BOLD signal change, whereas the $x$-axis indicates time (in seconds). D, Differential activation during attention versus saccade preparation. $E$, Differential activation during saccade versus pointing preparation. Target period is as follows: $F$, Group-average BOLD time courses, averaged over cue and target direction, extracted over the entire trial (the black arrow shows the time of cue onset, and the black arrow with mark shows the time of target onset, indicating the temporal window of stimulus presentation) in FEF, alPS, PCu, and IPL/alPS. G, Group-average $F(z) \mathrm{mc}$ map during attention plus target detection. H, Saccade plus target detection. I, Pointing plus target detection. L, Left; Calc.S, calcarine sulcus. The asterisk indicates that there were no active voxels in the left FEF after multiple-comparison correction. The FEF response during the attention task can be seen in Figure 3B. Data sets are available at http://pulvinar.wustl.edu:8081/sums/archivelist.do?archive_id = 315115 .

temporal sulcus (STS-mid), and in frontal cortex the dorsal precentral gyrus and the anterior cingulate. All of these regions were located in the left hemisphere contralateral to the responding hand. Finally, we compared pointing versus attention and found a pattern similar to that observed for pointing versus saccade
(Table $1 S$ ), except in the SPL and precuneus, in which the response for covertly directing attention was similar to the one for pointing preparation. Analogous results were obtained when we directly compared the three conditions (attention, saccade, pointing) in a three-way analysis (data not shown). 


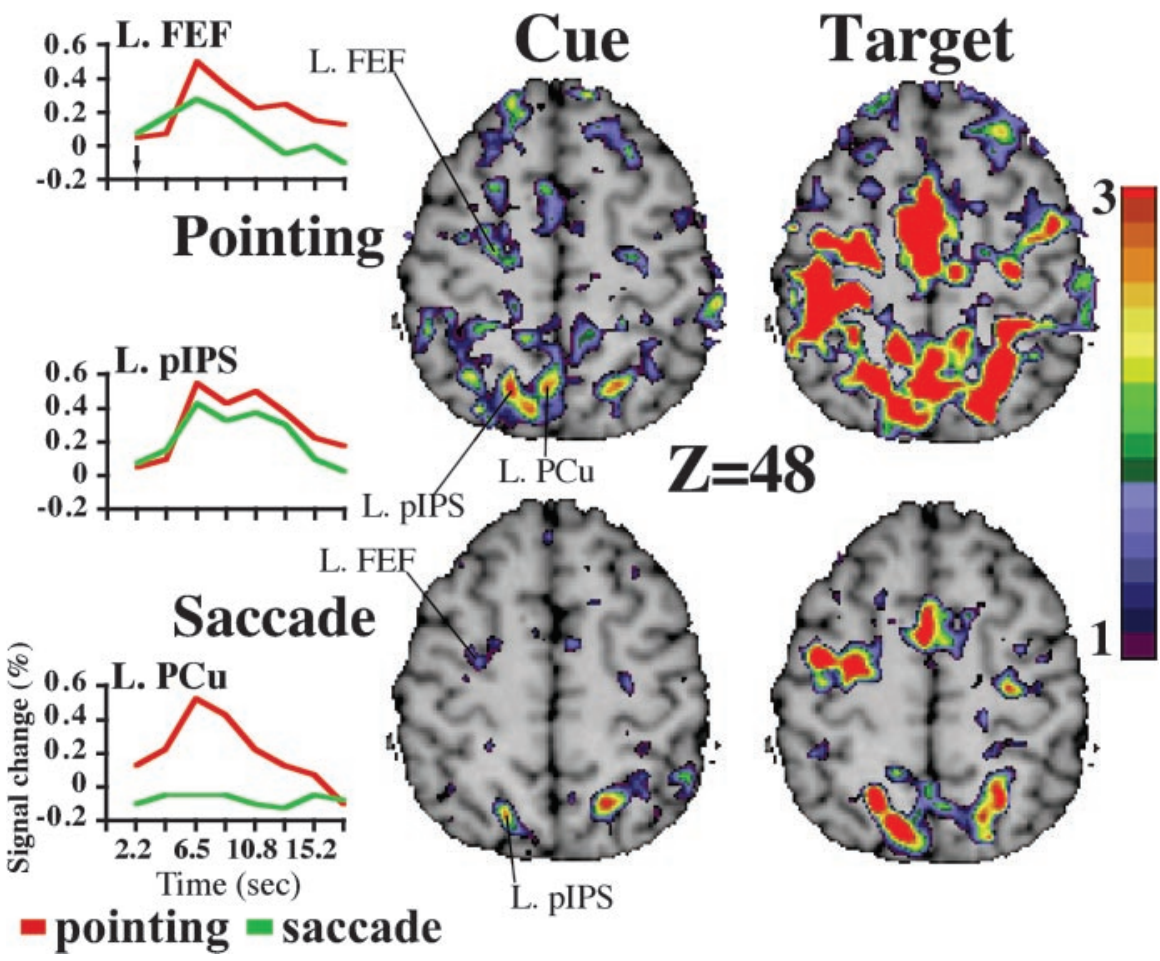

Figure 2. Selected transverse brain slices $(Z=48)$ during cue and target periods for pointing and saccade tasks in a representative subject. $T$-maps were transformed to $z$-maps. BOLD time courses, averaged over cue direction, were extracted from the left FEF, PCu, and pIPS.

The preparatory regions defined from the cue period also responded during the target period to the detection of the target and its localization by eye or hand movements (Fig. $1 G-I$ ). Figure $1 F$ shows the BOLD signal time course over an entire trial in four regions that showed preparatory signals during the cue period. The first peak is the response to the cue (Fig. $1 F$, black arrow, time axis), the sustained part of the response corresponds to the delay period, and the second peak corresponds to the detection/localization of the target (black arrow with mark). Anterior IPS and FEF regions, commonly active for attention and eye movement preparation, were more strongly active during the target period when subjects looked at the target location (saccade) than when they covertly detected the target (attention) (left FEF, $-29,-11$, $50, p<0.0001$; left aIPS, $-31,-51,46, p=0.0008$ ) (Fig. $1 F$, blue and green lines). The FEF showed a stronger response during the execution of a pointing movement than a saccade (left FEF, $p<$ 0.0001 ; right FEF, $p=0.0008$ ). Some regions that were specifically recruited during pointing preparation remained more strongly active during pointing than saccadic eye movements in the target period (Fig. $1 F$ ) (left IPL/aIPS, $p<0.0001$; left SMG, $p<0.0001)$. However, other regions did not show a differential response (Fig. $1 F$, left PCu, AG, STS-mid).

To localize the anatomical position of functional regions in the PPC and FC more precisely during saccadic and pointing preparation, we analyzed individual data in three subjects who were tested in a second session to double the number of trials. Figure 2 shows selected slices through the PPC and dorsal FC in a representative subject. As in the group analysis, the location of the FEF fell at the intersection of the superior frontal and precentral sulcus; its response was similar for the preparation of saccades and hand pointing (Fig. 2, FEF time course). The PPC response was within the posterior IPS and was not significantly different for saccades and pointing (Fig. 2, pIPS time course).
However, a region in the superior parietal lobule-precuneus was uniquely active during pointing (Fig. 2, PrCu time course). Other regions that were significantly more active during pointing preparation were the angular gyrus, left supramarginal gyrus, left dorsal precentral gyrus, and superior temporal sulcus. Importantly, these responses were all in the left hemisphere contralateral to the responding right hand in contrast to the bilateral FEF/IPS activation.

A critical question is whether left hemisphere regions that were recruited during the preparation of right-hand pointing movements are involved in the preparation of contralateral responses, or whether they are involved in preparing movements with either hand. Damage to the left parietal and frontal lobe in humans is known to cause bilateral deficits in planning complex hand or limb movements (apraxia) (Geschwind, 1975). To answer this question, 11 additional subjects prepared and executed pointing movements to visual targets with either the left or the right hand in different scans. None of the armspecific preparatory regions in experiment 1 were affected by switching the hand used to respond. A voxel-wise ANOVA indicated that only a left IPL/aIPS focus showed a significantly stronger response for left-hand (ipsilateral) pointing preparation $(x, y$, $z=-25,-51,38 ; p<0.0001)$. During the target period, only two of the preparatory regions from experiment 1 (left dorsal precentral gyrus, $p=0.0049$; left SMG, $p=0.018$ ) showed a significantly stronger response for right- versus left-hand pointing. In contrast, activations of the primary sensory-motor cortex and anterior cerebellum were contralateral and ipsilateral, respectively, to the hand used to point. These findings indicate that the response of these left-lateralized frontal and parietal regions is independent of the arm used to respond both during movement planning and during movement execution.

To compare these patterns of activation with the arrangement of cortical visual areas in the macaque, we registered the left hemisphere of a macaque atlas brain onto the left hemisphere of a human atlas brain, using a landmark-based surface matching method of Van Essen et al. (2001). This procedure allowed us to compare the parietal and frontal regions showing preparatory responses with an architectonic partitioning scheme of anatomical areas in monkey PPC developed by Lewis and Van Essen (2000). The interpretation of any set of results strongly depends on the assumptions used to register the human and macaque cortical surfaces. In this study, none of the landmarks used in the deformation were near the IPS or FEF, and none of the fMRI responses were used to constrain the deformation. This particular choice of landmarks yields a sensible registration of human and macaque extrastriate visual areas in the ventral occipital and temporal cortex (Van Essen, 2003).

Figure $3 A$ shows the anatomical areas in the macaque, and Figure $3 B$ shows the same macaque areas warped onto a corresponding view of the human left hemisphere. The intraparietal complex, including the LIP and ventral visual intraparietal area (VIP), is shown in yellow. The FEF (area 8) is red. 

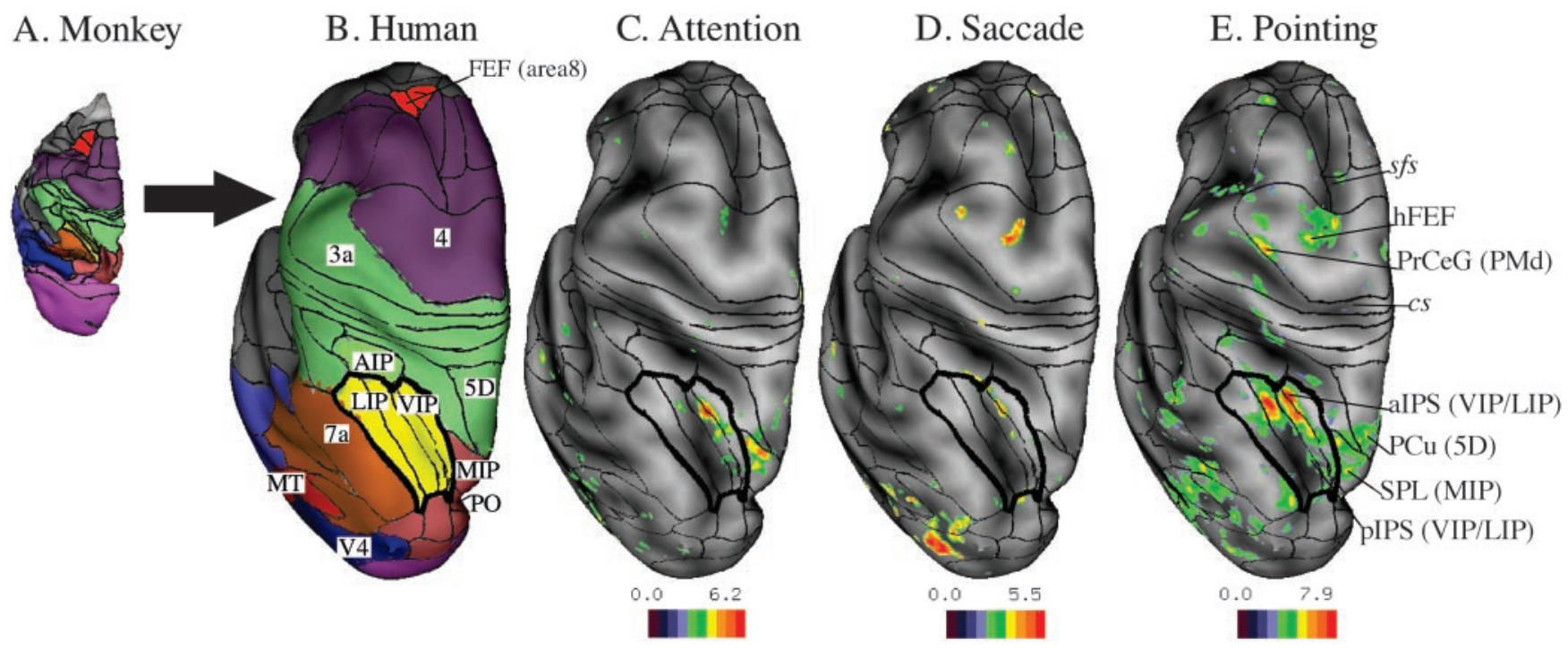

Figure 3. A, Macaque brain with anatomical areas (Lewis and Van Essen, 2000). B, Deformation and mapping of macaque areas onto a human atlas brain (left hemispheres, dorsal views) using surface-based registration. Red indicates the FEF (area 8), purple indicates motor areas (area 4), green indicates somatosensory areas (AIP, areas 5D and 3A), and yellow indicates visual parietal areas (LIP, VIP); the lines in each area define the LIP (dorsal and ventral) within the lateral intraparietal complex and VIP subdivisions (medial and lateral) within the ventral intraparietal area. Brown indicates other parietal areas (area 7A, PO), dark red indicates the MT, and blue indicates V4. C, Group-average ANOVA F( $z$ ) map, averaged over cue direction for attention. Black borders indicate deformed macaque visual areas painted in Figure 4A. D, $F(z)$ map during saccade preparation. $E, F(z)$ map during pointing preparation. Labels in italic indicate the anatomical landmarks. Abbreviations include anatomical locations in the human brain and a deformed area in the monkey (in parentheses): sfs, Superior frontal sulcus; cs, central sulcus; PrCeG, precentral gyrus; PMd, premotor dorsal. Data sets are available at http://pulvinar.wustl.edu:8081/sums/archivelist.do?archive_id $=315115$.

Table 1. Displacement in vector distance

$$
\left(V D=\sqrt{\left.(x 1-x 2)^{2}+(y 1-y 2)^{2}+(z 1-z 2)^{2}\right)}\right.
$$

between the PPC and frontal fMRI responses and monkey areas

\begin{tabular}{lrrrr}
\hline & $X$ & $Y$ & $Z$ & VD \\
\hline Parietal-occipital cortex & & & & \\
alPS & -31 & -49 & 51 & \\
pIPS & -30 & -61 & 49 & \\
aLIP & -36 & -54 & 50 & \\
pLIP & -32 & -58 & 39 & \\
alPS-aLIP & 5 & 5 & 1 & 7.1 \\
pIPS-pLIP & 2 & 3 & 10 & 10.6 \\
Frontal cortex & & & & \\
mFEF & -27 & 30 & 37 & \\
hFEF & -27 & -9 & 49 & \\
mFEF-hFEF & 0 & 39 & 12 & 40.8 \\
PrCeG & -40 & -9 & 52 & \\
6 dorso-caudal & -20 & 8 & 66 & \\
6 dorso-rostral & -16 & 20 & 51 & \\
PrCeG-6DC & 20 & 17 & 14 & 29.7 \\
PrCeG-6DR & 24 & 29 & 1 & 37.7 \\
\hline
\end{tabular}

Figure $3 D$ shows that preparatory activity for saccadic eye movements is distributed in an elongated crescent that falls within the deformed intraparietal visual complex (LIP, VIP) and maps within deformed area VIP on the medial bank of the IPS. In the macaque, preparatory activity for saccades is typically found on the lateral bank of the IPS within the LIP (Gnadt and Andersen, 1988; Snyder et al., 1997; Colby and Goldberg, 1999). The vector distance between the fMRI response for saccadic preparation and the center of the deformed LIP is $\sim 7 \mathrm{~mm}$ (Table 1). In the frontal lobe, the human FEF response for saccade preparation falls within deformed macaque area 4; this human response is displaced $\sim 4 \mathrm{~cm}$ posterior to the location of the deformed macaque FEF (mFEF) in the area 8 complex (Table 1).

Figure $3 C$ shows that covert attention activated a similar patch of cortex in the intraparietal complex (deformed areas VIP/LIP), a more dorsal and medial cluster in the SPL within the deformed medial intraparietal area (MIP) and the human FEF. Finally, pointing preparation (Fig. $3 E$ ) activated the intraparietal complex in a more widespread manner, with responses localized both on the medial and on the lateral side of the IPS, extending onto the lip of the supramarginal gyrus. Pointing also activated a more dorsal and medial swath in the SPL (Fig. 3E) that extended across deformed areas medial dorsal parietal area (MDP), MIP, parietaloccipital (PO), 5D, and 31 [anterior to deformed area V6A of Galetti et al. (1999)] (Fig. 1, supplemental material, available at www.jneurosci.org). In the frontal cortex, pointing preparation recruited the human FEF and dorsal precentral gyrus that corresponds to the human dorsal premotor area (Colebatch et al., 1991; Grafton et al., 1996; Connolly et al., 2000; Thoenissen et al., 2002). The dorsal precentral gyrus response maps in deformed area 4 and is displaced $>3 \mathrm{~cm}$ posterior from the deformed macaque dorsal premotor areas in area 6 (Table 1).

A convenient way to visualize regions of convergent or divergent activation is to project preparatory BOLD responses for all three conditions on the same atlas brain. Figure $4 A$ shows a dorsal view of the inflated surface of the left hemisphere of an atlas brain (Van Essen, 2002) on which group average preparatory signals for attention (blue), saccadic (green), and pointing (red) movements were projected. Regions of convergence between two conditions are indicated by intermediate colors (yellow, pointing and saccades; magenta, pointing and attention; light blue, attention and saccades); regions of convergence among three conditions are shown in white. The borders of the deformed macaque visual intraparietal complex (LIP/VIP) and the FEF area 8 complex are shown in black. Figure $4 B$ shows the flat map of the same left hemisphere.

We found two regions of convergence among all three conditions in the IPS (anterior and posterior) within the deformed visual intraparietal complex and one in the FEF at the intersection 

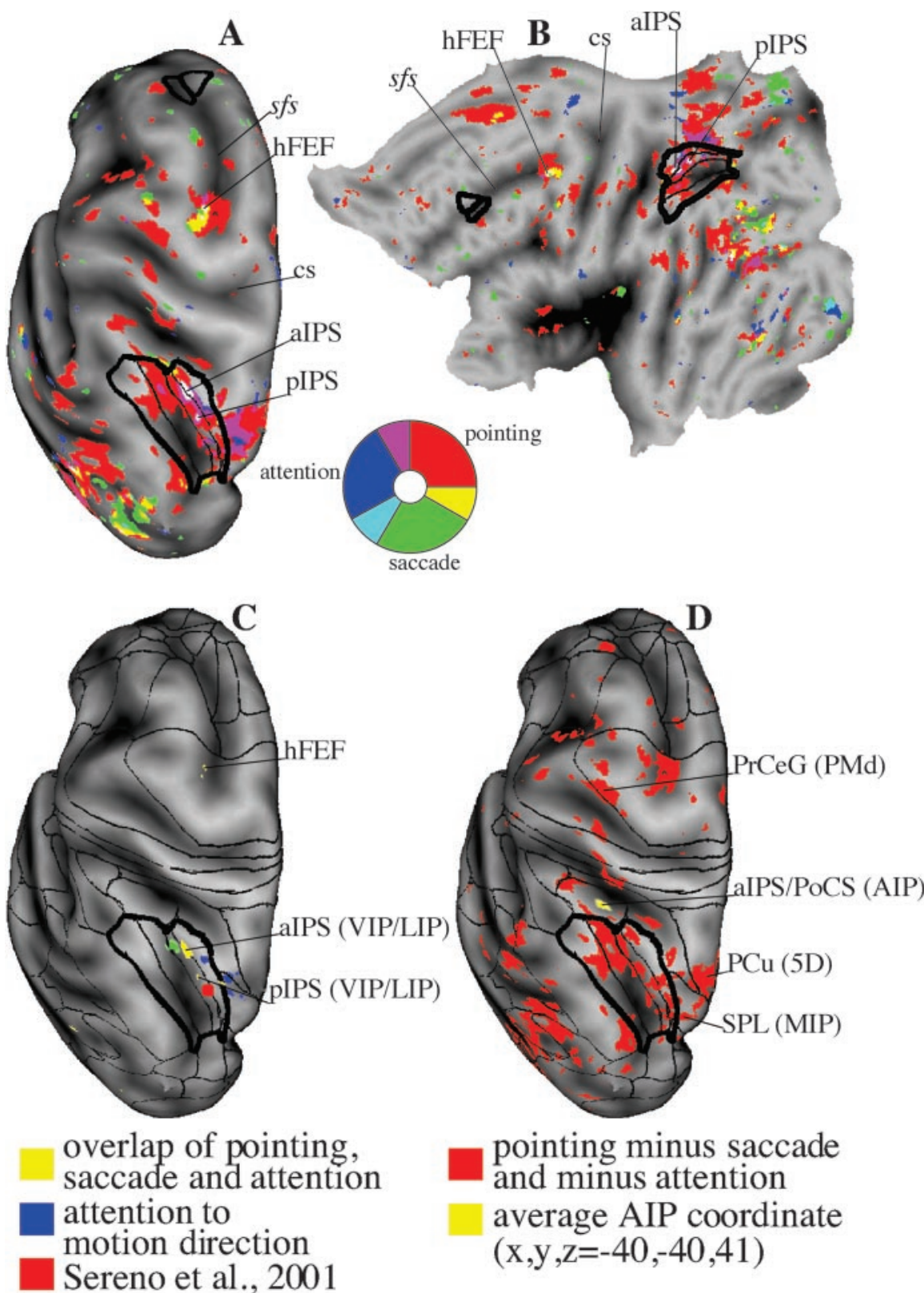

\section{Connolly et al., 2002}

Figure 4. Overlap of preparatory signals for attention (blue), saccade (green), and pointing (red). Regions of overlap are shown: White indicates all conditions, teal indicates attention/saccade, magenta indicates attention/pointing, and yellow indicates saccade/pointing. $A$, Left hemisphere, dorsal view. $B$, Flattened representation of the left hemisphere. $C$, Effectorindependent regions (i.e., overlap of preparatory signals for attention, saccade, and pointing preparation from Fig. $4 A$, $B$, yellow); foci of attention to motion direction from Shulman et al. (2002) are in blue. The retinotopically specific parietal area according to Sereno et al. (2001) is shown in red. The IPS area for preparation of saccadic eye movements described by Connolly et al. (2002) is shown in green. $D$, Hand-specific regions: responses for pointing preparation after subtraction of attention and saccade preparation from Figure $4 A$ (red); the coordinate of putative AIP averaged over several AIP human studies is shown in yellow (for review, see Binkofski et al., 1999; Grefkes et al., 2002). sfs, Superior frontal sulcus; cs, central sulcus; PoCS, postcentral sulcus; PrCeG, precentral gyrus; PMd, premotor dorsal.

of the precentral and superior frontal sulcus. The SPL (deformed area MIP) was active for both attention and pointing (Fig. $4 A, B$ )

Figure $4 C$ shows that the regions of common activation are adjacent to cortical regions active in a separate group of subjects in experiments that isolate preparatory signals for direction of motion (Shulman et al., 2002) (Fig. 4C, blue). The retinotopically organized parietal area reported by Sereno et al. (2001) is cen- tered nearby in the deformed VIP. The recent IPS region recruited during the preparation of prosaccades and antisaccades also plots within the deformed VIP (Connolly et al., 2002). A putative human homolog of VIP lies more anterior in correspondence of the anterior intraparietal (AIP) region (Fig. 4D) (Bremmer et al., 2001).

Figure $4 D$ compares the regions specifically recruited during pointing preparation with a nearby region at the intersection of the anterior IPS and postcentral sulcus (yellow; average coordinate $x, y, z$, $-40,-40,41)$ that is active during tasks that require grasping, manipulation, vision, or imagination of three-dimensional objects, visual and/or haptic (for review, see Binkofski et al., 1999; Grefkes et al., 2002). Lesions involving this more anterior region produce relatively greater deficits for grasping than reaching (Binkofski et al., 1998). This region has been proposed to be the human homolog of the AIP area identified in macaque by Sakata et al. (1995); deformed macaque AIP indeed maps anterior to the LIP/VIP complex.

\section{Discussion}

Our fMRI results suggest, contrary to our original hypotheses, that human PPC and FC contain several regions that code preparatory signals for spatial location independently of the effector used for the response (eye, arm). However, we also found regions for which activity was more closely related to the planning of pointing hand movements. For the particular landmarks chosen in this study, we found a higher spatial correspondence in the PPC between human fMRI responses and deformed anatomical areas in the macaque than in the frontal lobe, where large deviations were observed in the position of putatively homologous areas.

\section{Effector-independent preparatory spatial responses in IPS and FEF}

The anatomical overlap of IPS and FEF responses during spatial attention and eye movements was noted previously in blocked fMRI studies that averaged preparatory, visual, and motor-related activity (Corbetta et al., 1998; Nobre et al., 2000), but the present study is the first to show overlap of preparatory signals for saccades and covert spatial attention. A behavioral implication of this result is that spatial attention shifts are akin to the preparation of a saccadic eye movement, as suggested by a large body of psychophysical literature (Shepherd et al., 1986; Rizzolatti et al., 1987; Chelazzi et al., 1995; Hoffman and Subramaniam, 1995).

A novel and more surprising result was the recruitment of 
putative human FEF and IPS during pointing preparation and execution, insofar as these areas are traditionally considered oculomotor or attentional fields. Eye movement recordings in the scanner showed that subjects did not move their eyes during preparation or execution of pointing movements. It is also unlikely that fixation was more effortful while preparing an arm movement than an eye movement or a covert shift of attention. Our results are consistent with previous fMRI experiments that reported common activity in the IPS and FEF for visually guided saccades and pointing movements without separating preparation from execution (Connolly et al., 2000; Simon et al., 2002). The recruitment of IPS and FEF for pointing may seem to contradict previous single-unit studies that drew a strong distinction between areas involved in eye movements and attention (e.g., LIP, FEF) and regions involved in reaching (e.g., PRR) (Snyder et al., 1997). However, more recent studies have shown that neurons in the FEF (Lawrence and Snyder, 2002), and also in the LIP (Larry Snyder, personal communication), are recruited during the preparation and execution of visually guided reaching movements. Furthermore, whereas LIP and FEF neurons combine spatial and effector signals linearly, PRR neurons add them supralinearly during reaching (Dickinson et al., 2002). This suggests that the LIP and FEF code spatial locations in a more abstract (effector-independent) way than PRR, where the activity is more closely related to planning of arm movements.

The common recruitment, independent of response demands or type of effector, in the human IPS, macaque LIP, and FEF in both species is consistent with the view that neural signals in these regions are in part effector independent. The BOLD signal in these areas, which was sustained throughout the memory delay $(\sim 5 \mathrm{sec})$, may reflect the generation and maintenance of an attentional or memory signal coding the relevant spatial location, consistent with our hypothesis that these frontoparietal areas are attentional in nature and maintain an active representation of task-relevant information (Corbetta and Shulman, 2002). Alternately, this activity may reflect the use in all three tasks of intended eye-position signals to calculate the location of the attended target (Andersen et al., 1990; Duhamel et al., 1992; Batista et al., 1999). Eye position signals modulate BOLD responses in the IPS during reaching (DeSouza et al., 2000).

\section{Pointing-specific spatial responses in left posterior parietal and frontal cortex}

Pointing preparation recruited a larger number of regions than saccadic preparation or covert attention in the lateral and medial PPC and FC. This more widespread cortical recruitment may be related not just to the effector selected (arm rather than eye) but also to the more complex coordinate transformation necessary to plan a pointing movement (from a retinotopic to an armcentered frame of reference). Experiments that have manipulated coordinate transformations or the integration of retinotopic, eye, and arm position signals have observed signal modulations in PPC (Clower et al., 1996; DeSouza et al., 2000).

Pointing-specific preparatory responses were lateralized to the left hemisphere for both contralateral and ipsilateral movements. In contrast, the primary sensory-motor cortex switched with the hand used to point. These findings are consistent with the evidence that damage to the left inferior parietal lobule and frontal cortex causes spatial and temporal errors in planning bilateral voluntary movements or in the repetition of observed sequences or gestures (ideomotor apraxia) (Geschwind, 1975; Freund, 2001; Koski et al., 2002).

A cluster of pointing-specific activity involved a swath of tis- sue that extended from the SPL to the precuneus. Damage to the SPL causes optic ataxia in humans, a syndrome characterized by the inability to point precisely to visual targets (Perenin and Vighetto, 1988). Although responses in the SPL and precuneus have been reported previously during reaching and pointing (Kawashima et al., 1995; Grafton et al., 1996; Connolly et al., 2000; Simon et al., 2002), this is the first study to isolate preparatory activity. Based on the registration of cortical surfaces, we propose below that this region may partly correspond to the PRR in the macaque. This homology is suggested by the presence of arm-specific preparatory and motor activity as well as smaller but significant activity during saccadic eye movements (Fig. $1 F$ ). Similar signals have been recorded in the PRR (Snyder et al., 2000). Finally, we observed spatial attention responses in the SPL (Figs. 3C, $4 A, B$ ) consistent with the presence of pure spatial signals in the PRR in the absence of effector information (Calton et al., 2002).

A second left inferior parietal lobule cluster (mean coordinate, $-37,-49,46)$ was recruited during pointing preparation but not spatial attention. The lack of spatial attention signals may indicate that this region is more motor-related than the SPL/precuneus. This functional region is separate from putative human AIP (mean coordinate, $-40,-40,41$ ) (for review, see Binkofski et al., 1999; Grefkes et al., 2002), a region active during grasping and vision of three-dimensional objects that maps onto deformed macaque AIP (Fig. 4D). The lack of an AIP response probably reflects the fact that pointing does not involve complex hand movements.

Finally, the dorsal precentral gyrus corresponds to the dorsal premotor area, which is involved in preparatory set for finger and upper limb movements (Kurata, 1993; Schluter et al., 1998; Toni et al., 1999; Thoenissen et al., 2002). The anterior cingulate region corresponds to the cingulate motor areas that are closely connected with the dorsal and medial parietal lobe and involved in motor planning (Strick, 1988; Marconi et al., 2001)

\section{Macaque-human comparison}

Surface-based brain registration provides a general strategy for comparing cortical organization between species and evaluating candidate area homologies (Van Essen et al., 2001; Van Essen, 2003).

Our results suggest that humans and macaques share a more similar functional organization in the IPS than frontal cortex, insofar as the alignment of putatively homologous areas is concerned. Good correspondence between functional human regions and deformed macaque areas (e.g., IPS or SPL) is consistent with a common evolutionary plan coupled with a relatively uniform scaling of area sizes. In regions in which the correspondence is poor (e.g., FEF), multiple alternatives can be considered: differential expansion or contraction of some areas compared with others, divergence in the function of areas having a common evolutionary origin, emergence of entirely new areas and/or disappearance of others, and (most radically) overt transposition of cortical areas that alter their topological arrangement with neighbors.

The homologies proposed below are based on (1) the similarity between the human fMRI responses and the functional properties of neurons in anatomically defined macaque areas and (2) the registration of cortical surfaces. These homologies are provisional. More refined comparisons will emerge from direct interspecies comparisons of fMRI activation patterns using similar behavioral paradigms (Vanduffel et al., 2001; Nakahara et al., 2002). 
Two regions within the IPS (aIPS and pIPS) showed robust preparatory signals for saccades and attention, a prominent characteristic of LIP neurons (Gnadt and Andersen, 1988; Colby et al., 1996; Snyder et al., 1997), and notably, also for pointing. Both regions mapped to the deformed VIP/LIP complex (Figs. 3A-E, $4 A)$. Several factors might account for the modest mismatch between these foci and the center of the LIP $(\sim 7 \mathrm{~mm}$; Table 1$)$ : a genuine difference in the detailed topography of cortical areas within the human IPS, poor spatial resolution of the fMRI responses, anatomical variability attributable to intersubject averaging, or errors in the surface registration algorithm. In other studies, functional regions putatively homologous to LIP also fall on the medial wall of the IPS (Fig. 4C) (Corbetta et al., 1998, 2000; Sereno et al., 2001; Connolly et al., 2002).

Responses for attending to motion stimuli (Shulman et al., 2002) lie medial to the region for spatial attention and saccades (Fig. 4C) and may mark the location of human VIP. In the macaque, VIP neurons are strongly modulated by attention to motion (Cook and Maunsell, 2002). The response during pointing preparation in the lateral IPS and inferior parietal lobule (Figs. $3 E, 4 D$ ) may include parts of human $7 \mathrm{~A}$, an area that lies lateral to the LIP and contains neurons that fire before and during the execution of visually guided reaching movements (Mountcastle et al., 1975; Hyvarinen and Shelepin, 1979).

The topological relationship between effector-independent regions in the IPS and pointing-specific regions in the SPL/precuneus resembles the spatial arrangement of the LIP and PRR in the macaque (Rushworth et al., 2001). Activity for pointing preparation was mapped to several areas, including deformed the MIP, MDP, 5D, PO, and 31. Macaque MIP is part of the PRR (Colby and Duhamel, 1991; Calton et al., 2002). Other dorsomedial parietal areas (deformed MDP, 5D, and PO) are reciprocally connected in the macaque with dorsomedial frontal areas (dorsal premotor and anterior cingulate), which were also active for pointing preparation and form a specialized network for the coordinate transformation of peripheral visual information into reaching plans (Wise et al., 1997; Battaglia-Mayer et al., 2001; Marconi et al., 2001). An important caveat for our proposed homologies is that we studied finger-pointing movements in humans, whereas monkeys are usually studied during reaching movements.

Good spatial registration in the IPS and SPL/precuneus may be related to the conservation of basic attentional and visuomotor (saccades, reaching) processes in the course of evolution. Species differences (e.g., the medial displacement of LIP) may reflect the expansion of the left inferior parietal lobule, where human responses for phonology and calculation (Simon et al., 2002) may not have a counterpart in the macaque, and where hemispheric asymmetries have been demonstrated (Eidelberg and Galaburda, 1984).

In contrast to the relatively good alignment of human and monkey PPC, we found large deviations in the topography of putatively homologous areas in the frontal lobe (Fig. 4). For example, putative human FEF lies at the intersection of the superior frontal and precentral sulcus (Paus, 1996; Petit et al., 1997; Corbetta et al., 1998; Luna et al., 1998) and was displaced $\sim 4 \mathrm{~cm}$ posterior from the deformed macaque area 8 FEF complex (Fig. $3 D$ ). Similarly, the position of the macaque dorsal premotor area in area 6 is displaced $\sim 3 \mathrm{~cm}$ anterior from the human dorsal premotor area on the precentral gyrus.

Interestingly, both the monkey and human FEF lie near sulci that are oriented in a quasi-T intersection (arcuate and principalis sulci in the macaque; precentral and superior frontal sulci in humans). This may indicate that the larger shift in the topographical position of dorsal frontal areas is consistent with an emergence or expansion of prefrontal representations supporting the repertoire of cognitive, social, and emotional behaviors that characterize the human mind.

\section{References}

Andersen RA, Bracewell RM, Barash S, Gnadt JW, Fogassi L (1990) Eye position effects on visual, memory, and saccade-related activity in areas LIP and 7A of macaque. J Neurosci 10:1176-1196.

Andersson JLR (1995) A rapid and accurate method to realign PET scans utilizing image edge information. J Nucl Med 36:657-669.

Batista AP, Buneo CA, Snyder LH, Andersen RA (1999) Reach plans in eyecentered coordinates. Science 285:257-260.

Battaglia-Mayer A, Ferraina S, Genovesio A, Marconi B, Squatrito S, Molinari M, Lacquaniti F, Caminiti R (2001) Eye-hand coordination during reaching. II. An analysis of the relationships between visuomanual signals in parietal cortex and parieto-frontal association projections. Cereb Cortex 11:528-544.

Binkofski F, Dohle C, Posse S, Stephan KM, Hefter H, Seitz RJ, Freund HJ (1998) Human anterior intraparietal area subserves prehension: a combined lesion and functional MRI activation study. Neurology 50:1253-1259.

Binkofski F, Buccino G, Stephan KM, Rizzolatti G, Seitz RJ, Freund HJ (1999) A parieto-premotor network for object manipulation: evidence from neuroimaging. Exp Brain Res 128:210-213.

Bisley JW, Goldberg ME (2003) Neuronal activity in the lateral intraparietal area and spatial attention. Science 299:81-86.

Bizzi E (1968) Discharge of frontal eye field neurons during saccadic and following eye movements in unanesthetized monkeys. Exp Brain Res 6:69-80.

Boynton GM, Engel SA, Glover GH, Heeger DJ (1996) Linear systems analysis of functional magnetic resonance imaging in human V1. J Neurosci 16:4207-4221.

Bremmer F, Schlack A, Shah NJ, Zafiris O, Kubischik M, Hoffmann K, Zilles K, Fink GR (2001) Polymodal motion processing in posterior parietal and premotor cortex: a human fMRI study strongly implies equivalencies between humans and monkeys. Neuron 29:287-296.

Brodmann K (1905) Beitrage zür histologischen localisation der grosshirnrinde, dritte mitteilung: die rinderfelder der niederen affen. J Psychol Neurol 4:177-226.

Bruce CJ, Goldberg ME, Bushnell MC, Stanton GB (1985) Primate frontal eye fields. II. Physiological and anatomical correlates of electrically evoked eye movements. J Neurophysiol 54:714-734.

Calton JL, Dickinson AR, Snyder LH (2002) Non-spatial, motor-specific activation in posterior parietal cortex. Nat Neurosci 5:580-588.

Cavada C, Goldman-Rakic PS (1989) Posterior parietal cortex in rhesus monkey. I. Parcellation of areas based on distinctive limbic and sensory corticocortical connections. J Comp Neurol 287:393-421.

Chelazzi L, Biscaldi M, Corbetta M, Peru A, Tassinari G, Berlucchi G (1995) Oculomotor activity and visual spatial attention. Behav Brain Res 71:81-88.

Clower DM, Hoffman JM, Votaw JR, Faber TL, Woods RP, Alexander GE (1996) Role of posterior parietal cortex in the recalibration of visually guided reaching. Nature 383:618-621.

Colby CL, Duhamel J (1991) Heterogeneity of extrastriate visual areas and multiple parietal areas in the macaque monkey. Neuropsychologia 29:517-537.

Colby CL, Goldberg ME (1999) Space and attention in parietal cortex. Annu Rev Neurosci 22:319-349.

Colby CL, Duhamel JR, Goldberg ME (1996) Visual, presaccadic, and cognitive activation of single neurons in monkey lateral intraparietal area. J Neurophysiol 76:2841-2852.

Colebatch JG, Adams L, Murphy K, Martin AJ, Lammertsma AA, TochonDanguy HJ, Clark JC, Friston KJ, Guz A (1991) Regional cerebral blood flow during volitional breathing in man. J Physiol (Lond) 443:91-103.

Connolly JD, Goodale MA, Desouza JF, Menon RS, Vilis T (2000) A comparison of frontoparietal fMRI activation during anti-saccades and antipointing. J Neurophysiol 84:1645-1655.

Connolly JD, Goodale MA, Menon RS, Munoz DP (2002) Human fMRI evidence for the neural correlates of preparatory set. Nat Neurosci 5:1345-1352. 
Cook EP, Maunsell JH (2002) Attentional modulation of behavioral performance and neuronal responses in middle temporal and ventral intraparietal areas of macaque monkey. J Neurosci 22:1994-2004.

Corbetta M, Shulman GL (2002) Control of goal-directed and stimulusdriven attention in the brain. Nat Rev Neurosci 3:201-215.

Corbetta M, Akbudak E, Conturo TE, Snyder AZ, Ollinger JM, Drury HA, Linenweber MR, Petersen SE, Raichle ME, Van Essen DC, Shulman GL (1998) A common network of functional areas for attention and eye movements. Neuron 21:761-773.

Corbetta M, Kincade JM, Ollinger JM, McAvoy MP, Shulman GL (2000) Voluntary orienting is dissociated from target detection in human posterior parietal cortex. Nat Neurosci 3:292-297.

DeSouza JF, Dukelow SP, Gati JS, Menon RS, Andersen RA, Vilis T (2000) Eye position signal modulates a human parietal pointing region during memory-guided movements. J Neurosci 20:5835-5840.

Dickinson TR, Calton JL, Snyder LH (2002) Interactions between spatial and effector-specific information in two distinct areas of monkey posterior parietal cortex (PPC). Soc Neurosci Abstr 28:622.9.

Di Pellegrino G, Wise SP (1993) Effects of attention on visuomotor activity in the premotor and prefrontal cortex of a primate. Somatosens Mot Res 10:245-262.

Duhamel J-R, Colby C, Goldberg ME (1992) The updating of the representation of visual space in parietal cortex by intended eye movements. Science 255:90-92.

Eidelberg D, Galaburda AM (1984) Inferior parietal lobule. Divergent architectonic asymmetries in the human brain. Arch Neurol 41:843-852.

Forman SD, Cohen JD, Fitzgerald M, Eddy WF, Mintun MA, Noll DC (1995) Improved assessment of significant activation in functional magnetic resonance imaging (fMRI): use of a cluster-size threshold. Magn Reson Med 33:636-647.

Freund HJ (2001) The parietal lobe as a sensorimotor interface: a perspective from clinical and neuroimaging data. NeuroImage 14:S142-S146.

Galletti C, Fattori P, Kutz D, Gamberini M (1999) Brain location and visual topography of cortical area V6A in the macaque monkey. Eur J Neurosci 11:575-582.

Geschwind N (1975) The apraxias: neural mechanisms of disorders of learned movement. Am Sci 63:188-195.

Gnadt JW, Andersen RA (1988) Memory related motor planning activity in posterior parietal cortex of macaque. Exp Brain Res 70:216-220.

Grafton ST, Fagg AH, Woods RP, Arbib MA (1996) Functional anatomy of pointing and grasping in humans. Cereb Cortex 6:226-237.

Grefkes C, Weiss PH, Zilles K, Fink GR (2002) Crossmodal processing of object features in human anterior intraparietal cortex: an fMRI study implies equivalencies between humans and monkeys. Neuron 35:173-184.

Hoffman JE, Subramaniam B (1995) The role of visual attention in saccadic eye movements. Percept Psychophys 57:787-795.

Holmes CJ, Hoge R, Collins L, Woods R, Toga AW, Evans AC (1998) Enhancement of MR images using registration for signal averaging. J Comput Assist Tomogr 22:324-333.

Hyvarinen J, Shelepin Y (1979) Distribution of visual and somatic functions in the parietal associative area 7 of the monkey. Brain Res 169:561-564.

Kalaska JF, Scott SH, Cisek P, Sergio LE (1997) Cortical control of reaching movements. Curr Opin Neurobiol 7:849-859.

Kawashima R, Roland PE, O'Sullivan BT (1995) Functional anatomy of reaching and visuomotor learning: a positron emission tomography study. Cereb Cortex 5:111-122.

Koski L, Iacoboni M, Mazziotta JC (2002) Deconstructing apraxia: understanding disorders of intentional movement after stroke. Curr Opin Neurol 15:71-77.

Kurata K (1993) Premotor cortex of monkeys: set- and movement-related activity reflecting amplitude and direction of wrist movements. J Neurophysiol 69:187-200.

Lawrence BM, Snyder LH (2002) Effector specific and non-specific activity in frontal eye fields. Soc Neurosci Abstr 28:622.8.

Lewis JW, Van Essen DC (2000) Mapping of architectonic subdivisions in the macaque monkey, with emphasis on parieto-occipital cortex. J Comp Neurol 428:79-111.

Luna B, Thulborn KR, Strojwas MH, McCurtain BJ, Berman RA, Genovese CR, Sweeney JA (1998) Dorsal cortical regions subserving visuallyguided saccades in humans: an fMRI study. Cereb Cortex 8:40-47.
Marconi B, Genovesio A, Battaglia-Mayer A, Ferraina S, Squatrito S, Molinari M, Lacquaniti F, Caminiti R (2001) Eye-hand coordination during reaching. I. Anatomical relationships between parietal and frontal cortex. Cereb Cortex 11:513-527.

Mintun MA, Fox PT, Raichle ME (1989) A highly accurate method of localizing regions of neuronal activation in the human brain with positron emission tomography. J Cereb Blood Flow Metab 9:96-103.

Mountcastle VB, Lynch JC, Georgopoulos A, Sakata H, Acuna C (1975) Posterior parietal association cortex of the monkey: command function for operations within extrapersonal space. J Neurophysiol 38:871-908.

Nakahara K, Hayashi T, Konishi S, Miyashita Y (2002) Functional MRI of macaque monkeys performing a cognitive set-shifting task. Science 295:1532-1536.

Nobre AC, Gitelman DR, Dias EC, Mesulam MM (2000) Covert visual spatial orienting and saccades: overlapping neural systems. NeuroImage 11:210-216.

Ollinger J, McAvoy M (2000) A homogeneity correction for post-hoc ANOVAs in fMRI. NeuroImage 11:S604.

Ollinger JM, Shulman GL, Corbetta M (2001a) Separating processes within a trial in event-related functional MRI. I. The method. NeuroImage 13:210-217.

Ollinger JM, Corbetta M, Shulman GL (2001b) Separating processes within a trial in event-related functional MRI. II. Analysis. NeuroImage 13:218-229.

Ono M, Kubik S, Abernathey CD (1990) Atlas of the cerebral sulci. New York: Georg Thieme Verlag.

Passingham RE (1996) Attention to action. Philos Trans R Soc Lond B Biol Sci 351:1473-1479.

Paus T (1996) Location and function of the human frontal eye-field: a selective review. Neuropsychologia 34:475-483.

Perenin MT, Vighetto A (1988) Optic ataxia: a specific disruption in visuomotor mechanisms. I. Different aspects of the deficit in reaching for objects. Brain 111:643-674.

Petit L, Clark VP, Ingeholm J, Haxby JV (1997) Dissociation of saccaderelated and pursuit-related activation in human frontal eye fields as revealed by fMRI. J Neurophysiol 77:3386-3390.

Petrides M, Pandya DN (1999) Dorsolateral prefrontal cortex: comparative cytoarchitectonic analysis in the human and the macaque brain and corticocortical connection patterns. Eur J Neurosci 11:1011-1036.

Rizzolatti G, Riggio L, Dascola I, Umiltá C (1987) Reorienting attention across the horizontal and vertical meridians: evidence in favor of a premotor theory of attention. Neuropsychologia 25:31-40.

Rushworth MF, Ellison A, Walsh V (2001) Complementary localization and lateralization of orienting and motor attention. Nat Neurosci 4:656-661.

Sakata H, Taira M, Murata A, Mine S (1995) Neural mechanisms of visual guidance of hand action in the parietal cortex of the monkey. Cereb Cortex 5:429-438.

Schluter ND, Rushworth MF, Passingham RE, Mills KR (1998) Temporary interference in human lateral premotor cortex suggests dominance for the selection of movements: a study using transcranial magnetic stimulation. Brain 121:785-799.

Sereno MI, Pitzalis S, Martinez A (2001) Mapping of contralateral space in retinotopic coordinates by a parietal cortical area in humans. Science 294:1350-1354.

Shepherd M, Findlay JM, Hockey RJ (1986) The relationship between eye movements and spatial attention. Q J Exp Psychol A 38:475-491.

Shulman GL, Ollinger JM, Akbudak E, Conturo TE, Snyder AZ, Petersen SE, Corbetta M (1999) Areas involved in encoding and applying directional expectations to moving objects. J Neurosci 19:9480-9496.

Shulman GL, D’Avossa G, Tansy AP, Corbetta M (2002) Two attentional processes in the parietal lobe. Cereb Cortex 12:1124-1131.

Simon O, Mangin JF, Cohen L, Le Bihan D, Dehaene S (2002) Topographical layout of hand, eye, calculation, and language-related areas in the human parietal lobe. Neuron 33:475-487.

Snyder AZ (1995) Difference image vs. ratio image error function forms in PET-PET realignment. In: Quantification of brain function using PET (Myer R, Cunningham VJ, Bailey DL, Jones T, eds), pp 131-137. San Diego: Academic.

Snyder LH, Batista AP, Andersen RA (1997) Coding of intention in the posterior parietal cortex. Nature 386:167-170. 
Snyder LH, Batista AP, Andersen RA (2000) Saccade-related activity in the parietal reach region. J Neurophysiol 83:1099-1102.

Strick PL (1988) Anatomical organization of multiple motor areas in the frontal lobe: implications for recovery of function. In: Advances in neurology (Waxman SG, ed), pp 293-312. New York: Raven.

Talairach J, Tournoux P (1988) Co-planar stereotaxic atlas of the human brain. New York: Thieme Medical Publishers.

Thoenissen D, Zilles K, Toni I (2002) Differential involvement of parietaland precentral regions in movement preparation and motor intention. J Neurosci 22:9024-9034.

Thompson KG, Bichot NP, Schall JD (1997) Dissociation of visual discrimination from saccade programming in macaque frontal eye field. J Neurophysiol 77:1046-1050.

Toni I, Schluter ND, Josephs O, Friston K, Passingham RE (1999) Signal-, set- and movement-related activity in the human brain: an event-related fMRI study. Cereb Cortex 9:35-49.

Vanduffel W, Fize D, Mandeville JB, Nelissen K, Van Hecke P, Rosen BR, Tootell RB, Orban GA (2001) Visual motion processing investigated using contrast agent-enhanced fMRI in awake behaving monkeys. Neuron 32:565-577.
Van Essen D (2002) Windows on the brain: the emerging role of atlases and databases in neuroscience. Curr Opin Neurobiol 12:574-579.

Van Essen DC (2003) Organization of visual areas in macaque and human cerebral cortex. In: The visual neurosciences (Werner LCJS, ed), Cambridge, MA: MIT, in press.

Van Essen DC, Drury HA (1997) Structural and functional analyses of human cerebral cortex using a surface-based atlas. J Neurosci 17:7079-7102.

Van Essen DC, Lewis JW, Drury HA, Hadjikhani N, Tootell RB, Bakircioglu M, Miller MI (2001) Mapping visual cortex in monkeys and humans using surface-based atlases. Vision Res 41:1359-1378.

Van Essen DC, Drury HA, Harwell J, Hanlon D (2002) CARET userís guide and tutorial, Part I: surface-based atlases of cerebral and cerebellar cortex in human, macaque, and mouse. Published on-line at http://brainmap.wustl.edu/ caret/pdf/caret_users_guide_part1.pdf.

Walker E (1940) A cytoarchitectural study of the prefrontal area of the macaque monkey. J Comp Neurol 73:59-86.

Wise SP, Boussaoud D, Johnson PB, Caminiti R (1997) Premotor and parietal cortex: corticocortical connectivity and combinatorial computations. Annu Rev Neurosci 20:25-42. 